\title{
IV. Recensiones
}


REALA-1999, núm. 279. RECENSIONES

REALA-1999, núm. 279. RECENSIONES 


\section{Manzaña lagúáida, Rafaei: Situa- ciones administrativas de los Funcio- narios Públicos, Ediciones Revista Ge- neral de Derecho, Valencia, junio de 1998, 192 págs.}

Las situaciones administrativas son «uno de los aspectos menos transparentes y conocidos del régimen juridico funcionarial». Monográficamente, tan sólo cabe anotar la existencia de unos pocos artículos, algunos de ellos, como los clásicos de De la Vallina y Serrano Guirado, con más de cuarenta años a sus espaldas, siendo el más moderno el de Morillo Velarde («Las situaciones administrativas de los funcionarios en la Ley de Medidas para la Reforma de la Función Pública», REDA, n. ${ }^{\circ} 48$, Madrid, 1985).

La regulación "excesivamente casuística» de los supuestos que informan las situaciones administrativas, pese al carácter tasado de éstas, ha supuesto, en palabras de Íñigo Martínez de Pisón, la institucionalización del desorden «pues junto con el supuesto ordinario de situación de actividad, existen otros muchos (comisiones de servicio incontroladas, abuso de la libre designación, etc...), que suponen una auténtica desvertebración del sistema» (Íñigo Martinez de Pisón Aparicio, Régimen Juridico de la Función Pública y derecho al cargo, Universidad Complutense, Civitas, 1995, págs. 331 y ss.; citado por el autor en nota 48 al texto, pág. 29).

A poner un cierto orden, al menos didáctico, en la materia, viene el libro que hoy comentamos de Rafael Manzana, Magistrado de la Sala de lo Contencioso-Administrativo del Tribunal Superior de Justicia de la Comunidad Valenciana y autor de otras monografias sobre temas de Función Pública (Derechos y deberes de los funcionarios públicos, Tirant lo Blanch, Valencia, 1996, 342 págs.).

En la Introducción, el autor caracteriza a las situaciones administrativas con estas cuatro notas: 1) la dicotomía entre una situación «normal» -la de servicio activo- y el resto de las situaciones administrativas «excepcionales». 2) Su carácter de encrucijada entre los intereses de la administración en la adecuada prestación de los servicios y las conveniencias particulares de los funcionarios. 3) Su régimen tasado y 4) la propia variabilidad histórica del número y régimen jurídico de las situaciones cuya evolución hay que verla vinculada «a los privilegios de los Cuerpos Especiales de funcionarios, y por ello su regulación se ha producido de forma desconexa y carente de una visión unitaria» (pág. 11).

El autor, tras de trazar un breve panorama histórico del régimen de las situaciones administrati- vas, se introduce en el marce normativo vigente, destacando el carácter básico de la regulación de las situaciones administrativas (art. 29 de la Ley 30/1984), sin que de tal carácter básico imponga «una absoluta identidad y uniformidad de su regulación para los distintos colectivos funcionariales»" (STS 18.6.1993), su carácter de numerus clausus «y al propio tiempo, en virtud de la reserva de Ley que pesa sobre la materia estatutaria, no cabe una regulación autónoma mediante instrumentos reglamentarios, ni se trata de aspectos susceptibles de negociación colectiva, a diferencia de lo que procede en el sector laboral» (pág. 20 y nota 40 a pie de página).

El resto de la obra consiste en un análisis individualizado de cada uno de los tipos de situaciones administrativas: de una parte, el servicio activo $y$, de otra, por comparación, otras situaciones administrativas distintas del servicio activo, supuestos en que proceden y régimen juridico: servicios especiales, servicios en Comunidades Autónomas, expectativa de destino, excedencia en sus distintas modalidades, excedencia para el cuidado de hijos y suspensión de funciones. Sazonan el texto un número considerable de referencias normativas y citas jurisprudenciales, totalizando 235 a pie de página.

Completa el conjunto un estudio de los cambios en las situaciones administrativas y del reingreso al servicio activo desde cada una de ellas.

Hay una breve descripción de las distintas situaciones administrativas en el anteproyecto de Estatuto Básico de la Función Pública de 30 de septiembre de 1997 (texto anterior al remitido al Consejo de Estado fechado en octubre de 1997), cerrando la obra la transcripción de la normativa vigente que ocupa 47 de las 192 páginas del texto.

En resumen, se trata de un apunte monográfico no demasiado extenso, sobre una zona oscura de la Función Pública, cuya lectura puede resultar de interés para el operador jurídico encargado de la interpretación o aplicación de la normativa.

Manuel Martínez Bargueño

\section{González Pérez, Jesús: Justicia $A d$ - ministrativa. Legislación y Jurispru- dencia del Tribunal Supremo y del Tri- bunal Constitucional, Civitas, Ma- drid, 2." edición, 1999, 717 págs.}

La esperada reforma de la justicia administrativa cuenta ya con un práctico instrumento para la consulta rápida, pero a la vez exhaustiva, de toda la problemática que encierra el control de la actuación administrativa. No puede desconocerse que 
un completo conocimiento del ordenamiento que consagra las garantías del administrado no sólo exige un ordenado y concordado código de la normativa vigente, sino además una selección y sistematización de la doctrina jurisprudencial habida en la materia. La profunda y reciente modificación experimentada en este sector, unida a la convicción de que cualquier reforma legislativa es siempre fruto de una evolución y una previa experiencia, hacen conveniente, qué duda cabe, la comprensión de toda esta novel regulación a la luz del tejido jurisprudencial diseñado a lo largo de los años a partir de la aplicación e interpretación del Derecho, en cuanto verdadero «cordón umbilical» entre tal normativa y la práctica del pasado.

Esta perfecta simbiosis entre legislación vigente y jurisprudencia se alcanza con toda plenitud en el trabajo recensionado, viniendo a suponer los diferentes autos y sentencias el relleno más adecuado para una normativa de tan reciente aparición.

Si en la primera edición de esta obra, fechada en 1992, el profesor González Pérez ofreció ya, con motivo de la reforma operada en el contencioso por la Ley 10/1992, de 30 de abril, de Medidas Urgentes de Reforma Procesal, una ordenada y completa exposición del cuerpo legal, jurisprudencial y doctrinal de la antigua Ley de 27 de diciembre de 1956, entonces con el título de Ley de la Jurisdicción Contencioso-Administrativa (Jurisprudencia del Tribunal Supremo y del Tribunal Constitucional), en esta segunda edición el autor ha vertido este esfuerzo a una más amplia regulación, omnicomprensiva de lo que puede considerarse, en sentido amplio, justicia administrativa. No sólo, por tanto, la vigente Ley reguladora de la Jurisdicción Contencioso-Administrativa, 29/1998, de 13 de julio, encuentra en la actualidad acomodo en esta obra, sino también algunos de los preceptos de la Ley Orgánica 6/1985, de 1 de julio, del Poder Judicial, modificada por Ley Orgánica 6/1998, de 13 de julio; algunas de las disposiciones de la Ley 50/1997, de 27 de noviembre, del Gobiemo; así como de la Ley 50/1998, de 30 de diciembre, de Medidas Fiscales, Administrativas y del Orden Social; junto a la Ley 30/1992, de 26 de noviembre, de Régimen Jurídico de las Administraciones Públicas y del Procedimiento Administrativo Común, en su última redacción dada por Ley 4/1999, de 13 de enero; el Reglamento de los procedimientos de las Administraciones Públicas en materia de responsabilidad patrimonial, aprobado por Real Decreto 429/1993, de 26 de marzo; y el Reglamento del procedimiento para el ejercicio de la potestad sancionadora, aprobado por Real Decreto 1398/1993, de 4 de agosto.

Precisamente, la exhaustividad en el tratamiento del objeto de la obra, la absoluta actualización de las fuentes y datos manejados, así como su práctico y fácil manejo (al aportarse la informa- ción jurisprudencial con motivo de cada precepto y apartado, junto a ilustrativas notas a pie, e índice analítico final), representan los aspectos más sobresalientes en una obra que parece cumplir con todos los requisitos para ocupar un pequeño espacio - pues pequeño es su formato, en contraste a su contenido- en las estanterias y mesas de trabajo de los diferentes operadores juridicos.

Luis Ángel Ballesteros Moffa Universidad de León

\section{GaRCíA RoCA, Javier (Coord.): Dere- cho público de Castilla y León, Univer- sidad de Valladolid, 1999, 665 págs.}

Uno de los indicadores del desarrollo del Estado de las Autonomias se encuentra en el crecimiento exponencial de la literatura juridica dedicada a temas de Derecho autonómico de cada Comunidad Autónoma. Si en un primer momento la doctrina se ocupó de las grandes incógnitas que planteaba el Título VIII de la Constitución y, más adelante, de la aprobación de los Estatutos, ya desde mediados de los ochenta empiezan a aparecer estudios monográficos sobre cuestiones de Derecho público catalán, vasco, y así sucesivamente. Son pioneras en este proceso las Revistas autonómicas de Derecho público que asumieron la tarea de dar a conocer a toda la comunidad jurídica los avances normativos de las Comunidades (y nacionalidades) vanguardistas en la creación de un ordenamiento jurídico peculiar: Autonomies (Revista catalana de Derecho público), la Revista Vasca de Administración pública, la Andaluza, la Gallega, la Aragonesa o la Valenciana. La mejor prueba del actual grado de desarrollo del Derecho autonómico la podemos encontrar en los escaparates de las librerias juridicas, donde hoy vemos estudios sobre la forma de gobierno en Andalucía o el Derecho urbanístico de Castilla-La Mancha o la Comunidad de Madrid.

A estas obras viene a sumarse, con pretensiones de generalidad (yo diría que casi logradas) el $D e$ recho público de Castilla y León de Javier GARcía Roca, Catedrático de Derecho Constitucional de la Universidad de Valladolid, que recientemente también nos ha ofrecido un interesantísimo estudio sobre el artículo 23:2 de la Constitución (Cargos públicos representativos. Aranzadi, 1999). El libro aquí recensionado agrupa las ponencias presentadas en unas Jornadas celebradas en Valladolid durante los meses de noviembre y diciembre de 1997, patrocinadas tanto por la Universidad de Valladolid como por el Instituto Nacional de Administración Pública y la Junta de Castilla y León. Así nos lo recuerda el coordinador en su Prefacio, en el que, amén de los agradecimientos obligados, se realizan unas breves observaciones 
sobre la realidad territcrial de Castilla y León, ciertamente oportunas en el momento en que ya se han sentado algunas de las bases normativas necesarias para emprender una politica de ordenación del territorio en esta Comunidad Autónoma.

Los contenidos de la obra abarcan todos los aspectos del Derecho público de la Comunidad Autónoma, lo que equivale a la práctica totalidad del Derecho de Castilla y León. Con mínimas excepciones, todo lo importante se puede encontrar en el índice del volumen y a lo largo de sus condensadas páginas. El libro se divide en nueve partes, las ocho primeras dedicadas a los siguientes temas: la formación de la Comunidad Autónoma y sus elementos (iniciativa autonómica y elaboración del Estatuto); las instituciones de autogobierno (Cortes, Presidente, Junta, Tribunal Superior de Justicia, Consejo Económico y Social, Procurador del Común); las Administraciones públicas (Organización, función pública, Administración local, régimen de las disposiciones y resoluciones administrativas); las relaciones con el Estado (ordinamentales, de cooperación y conflicto); las relaciones con la Unión Europea y la actividad exterior (proceso de integración europea y cooperación transfronteriza); las competencias autonómicas; la Hacienda de la Comunidad y la reforma del Estatuto. El noveno apartado contiene los debates que se desarrollaron en dos mesas redondas: "La vida parlamentaria en la realidad» y «Financiación de las Comunidades Autónomas»; temas todos ellos sin desperdicio, desde luego.

Destacar alguna de las colaboraciones presentadas sería osado por mi parte, teniendo en cuenta que casi están todos los que son y son todos los que están, la flor y la nata del Derecho público castellano-leonés. Claro, que al igual que faltan algunos temas importantes, también echamos de menos entre los autores a algunos de los ilustres iuspublicistas de la Comunidad Autónoma, especialmente de las Facultades de Derecho de León y Salamanca. Pero, ausencias aparte, es preciso reconocer que el esfuerzo desarrollado por todos los autores es digno de nuestro reconocimiento, $y$ todos pueden sentirse orgullosos de haber puesto algo más de un grano de arena en la construcción de estos que son mucho más que comentarios a la normativa autonómica. Desde la publicación de otra obra clave sobre el Derecho de esta Comunidad Autónoma (los Comentarios al Estatuto de Autonomia publicados por el IEAL en 1985, dirigidos por RIVERo YSERN) habian pasado demasiados años sin ningún otro tratamiento exhaustivo del Derecho castellano-leonés.

No resulta en absoluto original, ni valiente, quitarle, una vez más la razón a voN KIRCHIMANN, cuando dijo que tres palabras rectificadoras del legislador convertian bibliotecas enteras en papel de desecho. Ni la reforma de! Estatuto de Autonomía de Castilla y León, aprobada por Ley Orgánica 4/1999, de 8 de enero, ni la aprobación de algunas importantes leyes por las Cortes castellanoleonesas (Régimen local, Ordenación del territorio...). restan valor a este libro que por su contenido debe ser estudiado por todos los que nos interesamos en esta materia. Su público mayoritario (funcionarios de la Comunidad Autónoma o aspirantes a serlo, estudiantes de Derecho en Facultades con planes de estudio en los que se contemple una asignatura con este temario, estudiantes de gestión y administración pública, abogados ejercientes en Castilla y León) no se verá defraudado por el texto adquirido. Ahora bien, pedirá más, probablemente, pues comprenderá la utilidad de un intento recopilador y sistematizador como éste, con una vocación tal vez más humilde, pero pragmáticamente tan necesario como la codificación. Exactamente igual que son necesarias recopilaciones normativas actualizadas de Derecho autonómico (asignatura pendiente), a ser posible anotadas y concordadas, hace falta profundizar periódicamente (anualmente, a lo sumo) en el estado de evolución del Derecho de la Comunidad Autónoma. Una vez comenzada esta tarea no se puede abandonar.

$\mathrm{Al}$ iniciar esta recensión apuntaba el protagonismo asumido por las Revistas autonómicas de Derecho público en el estudio del nuevo Derecho de las Comunidades Autónomas. También he intentado poner de relieve el tremendo vacío que viene a cubrir la obra coordinada por GARCí ROCA. Llegados a un punto de desarrollo competencial y estatutario como el que presenta la última reforma del Estatuto de Autonomía de Castilla y León, tal vez sea hora de que las Instituciones autonómicas castellanoleonesas se planteen seriamente, aprovechando la oportunidad de una próxima creación del Consejo Consultivo, la necesidad de constituir foros de opinión y difusión, centros de estudio y debate de la realidad política e institucional de esta Comunidad, que no por llegar la última al status de Autonomía debe ser considerada la menos decidida a afrontar hasta sus últimas consecuencias el gran desafio que todavia hoy plantea la realización eficaz del Estado de las Autonomías.

Ricardo Rivero Ortega

Profesor Titular de Derecho administrativo de la Universidad de Salamanca

\section{BARATA I MIR, Joan: Los actos de go- bierno en el ámbito municipal, Tecnos, Madrid, 1999, 227 págs.}

Bien hubiera podido incluirse esta monografia en la colección de Temas Clave de la Constitución española dirigida por el Profesor DE VEGA, ya que el objeto de estudio es fundamentalmente una de- 
claración constitucional - la del artículo 140 de nuestra norma suprema- que se refiere al gobierno y la administración de los municipios. No esta de más, sin embargo, su incorporación a Ventana abierta, cuya linea parece decantarse por los temas polémicos o necesitados de debate. En este caso, además, estamos ante un tema lastrado por tópicos que quizás ya va siendo hora de superar definitivamente, como el que se deriva de la declaración de la jurisprudencia del Tribunal Constitucional de que la autonomia local es puramente administrativa, en un sistema en el que todavía no parece suficientemente nítida la distinción entre lo politico y lo administrativo.

$\mathrm{Y}$, sin embargo, tanto a nivel orgánico como a nivel procedimental se reconocen instancias de decisión política, como demuestran nuestro Derecho positivo (artículo 3.3 de la Ley 30/1992) y la doctrina constitucional (STC 45/1990). Este reconocimiento es unánime cuando se analiza la actividad de las Comunidades Autónomas, probablemente por su ejercicio de la potestad legislativa, lo que no ocurre cuando se estudia la actividad de los Entes locales. La última manifestación de la exclusión normativa del componente político de las decisiones locales se encontraría en el artículo 2.a) de la nueva Ley reguladora de la Jurisdicción contencioso-administrativa (Ley 29/1998), que contempla un régimen especial de control de los actos de gobierno a nivel estatal y autonómico, sin mencionar para nada los actos de gobierno local.

Qué sea político y qué sea administrativo: no estamos ante una dicotomía trivial, precisamente, pues alguna consecuencia de régimen juridico habremos de extraer de una u otra calificación, consecuencia que debe ser sin embargo aceptable en un contexto en el que, con independencia del nombre de los poderes públicos $-y$ de su naturale$\mathrm{za}$-, todos están sujetos a determinados principios limitadores de su intervención. Político no significa exento de control, dato reconocido tanto por el autor del libro recensionado como por su prologuista, el Profesor Font i Llovet. Ahora bien, la naturaleza y la intensidad del control pueden variar en función de la naturaleza de la decisión fiscalizable.

El contenido de la obra recensionada se divide en tres capitulos. El primer capitulo intenta definir lo que sea la actividad de gobierno, misión dificil - tal vez tanto como definir la actividad de administración- pero posible si tenemos en cuenta que tanto en la Constitución como en la jurisprudencia - del Tribunal Supremo y del Tribunal Constitucional - se reconoce la existencia de una especifica actividad de gobierno; el capítulo II contiene una aproximación a aquellas decisiones municipales que pueden considerarse de gobierno (no de administración): las declaraciones políti- cas; la moción de censura al Alcalde; el ejercicio de la potestad reglamentaria y las consultas populares tendrian un carácter político, no meramente administrativo. Por último, el capitulo III recoge conclusiones, referidas fundamentalmente a la necesaria recuperación de la categoría acto de gobierno, amparada por la legitimidad democrática que reciben determinados poderes ejecutivos (estatal, autonómico, municipal), cuyo control no debe ejercerse únicamente en términos de Derecho, aunque este control sea perfectamente legitimo cuando estos poderes se hayan juridificado, introduciendo elementos reglados que, sin embargo, integran decisiones adoptadas de acuerdo con impulsos no reglados juridicamente.

Del concepto de autonomía local derivaría la existencia de un ámbito de gobierno local, que probablemente no es accesible acudiendo a la tan socorrida figura de la garantía institucional. BARATA I MiR rechaza esta categoría por la ausencia de tradición jurídica de la autonomía local, que impide un juicio de las medidas que se adopten en términos de recognoscibilidad de la institución. Podriamos recordar aquí las brillantes observaciones de Gallego Anabitarte en torno a la figura. Puede ser mucho más oportuno $-\mathrm{y}$ el autor lo apunta- utilizar el concepto garantia constitucional, garantía traducible en términos de independencia funcional. La intervención de los legisladores estatal y autonómico debe respetar un contenido que, más allá del Título VIII, encontramos en la Carta Europea de la Autonomía Local. Los aspectos del régimen local estudiados especialmente (declaraciones políticas, mociones de censura, aprobación de ordenanzas y consultas populares) deberían reflejar la realidad del gobierno local.

Las declaraciones politicas, por ejemplo, no son subsumibles en el concepto de acto administrativo - extremo que apunta el autor- pues pese a ser tal vez caracterizables como declaraciones de juicio, y ser emitidas por un órgano que ejerce funciones administrativas, lo cierto es que el Pleno de un Ayuntamiento no es solamente un órgano administrativo, ni en estos casos estamos ante el ejercicio de una potestad administrativa distinta de la potestad reglamentaria, como demuestra el dato de que no son extensibles a este tipo de declaraciones los privilegios de ejecutividad y ejecutoriedad de los actos administrativos. No estamos ante casos de autotutela, sino ante una consecuencia de la naturaleza comunicativa del Poder politico: pura opinión, que podría encuadrarse mientras no tenga efectos vinculantes ni innovadores del ordenamiento en un matizado derecho a la libertad de expresión (el autor lo encuadra en el escasamente regulado derecho de petición) que corresponderia a las autoridades municipales. Distinta cuestión es, sin embargo, que este tipo de declara- 
ciones, formalizadas en acuerdos, puedan ser impugnadas por los Concejales que hayan votado en contra, con la legitimación que les reconoce la LBRL, pudiendo producirse una revisión jurisdiccional de dichos acuerdos en la medida en que puedan haber violado algún derecho (a la participación, por ejemplo) o constituyan excesos manifiestos del ámbito competencial de la Corporación (que afecten a cuestiones propias de otro Municipio, o de otra Comunidad). BARATa I MIR, sin embargo, no ve problemas en exceder el propio ámbito municipal, toda vez que se trata solamente de una toma de postura. Aquí, no obstante, podria invocarse algún precepto legal en sentido contrario, como el artículo 4 de la Ley 30/1992 (Principios de las relaciones entre Administraciones publicas), en su apartado 1.a): «Las Administraciones Públicas, en el desarrollo de su actividad y en sus relaciones reciprocas, deberán: Respetar el ejercicio legitimo por las otras Administraciones de sus competencias»).

Con respecto al tema de las Mociones de censu$\mathrm{ra}$, el autor señala su fundamento en el artículo 140 de la Constitución, que legitima una aplicación en el ámbito municipal del sistema de confianza politica propio de los regimenes parlamentarios (generalizados también a nivel autonómico). No repara, sin embargo, en que la LOREG, que introduce en nuestro Derecho una posibilidad antes admitida por la Jurisprudencia, contempla también en su artículo 207 la destitución del Presidente de la Diputación, aplicando el procedimiento previsto para el cese del Alcalde en su artículo 197. Esta previsión complica el puro entronque de la moción con el artículo 140, pues no cabe duda de que el principio representativo es distinto en los Municipios y en las Diputaciones. Aunque debe reconocerse que al menos en ambas instituciones existe un componente político que ampara la necesidad de un procedimiento de esta naturaleza. Componente político que no empece, sin embargo, su juridificación, es decir, el establecimiento de unos presupuestos, un procedimiento y un control jurisdiccional ulterior de la decisión adoptada, juridificación que puede incluso llegar a interferir de lleno en la oportunidad de las mociones de censura si se aplicaran las medidas previstas sobre este punto en el Pacto Local, que contempla límites a la presentación de las mociones de censura cuando se aproximen las elecciones municipales. No cabe duda de que en política pueden producirse pactos entre caballeros, como el aplicable al transfuguismo, pero de ahí a que se limite el presupuesto de hecho habilitante por una razón temporal, y que esta limitación no sea prevista en el reglamento orgánico de cada Corporación, hay toda una serie de incógnitas que ponen de nuevo sobre el tapete el problema inicial: la posición real de los Ayuntamientos y el componente realmente político de la autonomía local.
La aprobación de reglamentos municipales, es decir, de ordenanzas, es otro de los ejemplos de medidas de gobiemo municipal estudiados, haciendo especial hincapié en el procedimiento $y$, en concreto, en la iniciativa para la aprobación de una ordenanza, que se adopta sin duda atendiendo a valoraciones de oportunidad. Así, aqui parece extensible la jurisprudencia constitucional en cuanto a los actos del Gobiemo de iniciativa legislativa. Siempre y cuando, claro esta, la iniciativa no se regule en términos muy detallados, lo que puede suceder si las Comunidades Autónomas siguen el ejemplo del Reglamento de Oganización, Funcionamiento y Régimen Juridico de las Entidades locales aprobado para Cataluña, que contempla un procedimiento específico con más detalle que el articulo 49 LBRL (una norma de mínimos). Tal vez debiera ser el propio Reglamento orgánico de cada Entidad local el que contemplara este procedimiento, ya que autonomía tiene mucho que ver con la capacidad para dictarse sus propias normas, la potestad autoorganizatoria. Y la forma de decidir estas normas no es precisamente trivial. Si se juridifica este procedimiento, puede suceder que sea controlable la decisión de no aprobar determinada norma. No se olvide, por otra parte, que alguna legislación autonómica de régimen local contempla la aprobación de ordenanzas municipales subsidiarias -en materia urbanística, por ejemplo- por parte de la Comunidad Autónoma. Si ésta es una decisión de gobierno, mal parado queda el gobiemo municipal.

Por último, la regulación de las consultas populares (el ejemplo más complicado, a juicio del autor), cuyos mínimos procedimentales se hallan en el artículo $71 \mathrm{LBRL}$, demuestra la existencia de un acuerdo de naturaleza política adoptado por la Corporación que, sin embargo, puede ser desautorizado por el Gobierno, que ejerce aquí un verdadero control de oportunidad, curiosamente además en una cuestión de la competencia propia municipal y de carácter local, que resulta además de especial importancia para los intereses de los vecinos. Sin duda estamos ante otra reserva de nuestro ordenamiento para con uno de los principales mecanismos de democracia directa. Si la decisión de proponer convocatoria de referéndum es, como señala BARATA I MIR, una decisión predominantemente política, lo que limita las posibilidades de control jurisdiccional siempre que afecta a la esfera competencial del municipio, igualmente politica parece la decisión del gobierno de autorizar o no la convocatoria, pues no estamos ante una autorización reglada, pese a que el Consejo de Estado califique esta intervención como control de legalidad. El autor reconoce un control de oportunidad en esta autorización, incluso se plantea su naturaleza como acto de gobierno. Estamos ante una paradoja - una decisión política municipal mediatizada o subordinada a una decisión gubernamen- 
tal-que dificilmente se puede resolver sólo con la apelación a la lealtad institucional.

La única solución parece ser, de nuevo, la densificación juridica de las decisiones y su procedimentalización. Lo reglado y lo discrecional es todavía, en último término, el criterio mas fiable para distinguir el componente político del componente administrativo de las decisiones ejecutivas. Al menos mientras el control jurisdiccional de las decisiones de poder público sea el principal mecanismo de fiscalización de las decisiones - políticas y administrativas - en nuestro ordenamiento. Lo que no quiere decir que sea el único posible, ni necesariamente el más adecuado en todo caso.

Ricardo Rivero Ortega

Profesor Titular de Derecho administrativo de la Universidad de Salamanca

\section{GARCÍA DE COCA, J. A.: Liberalización de la actividad funeraria, Secretariado de Publicaciones e Intercambio Cien- tífico, Universidad de Valladolid, 1998.}

«Ni el sol ni la muerte pueden ser mirados fijamente». Con tan pocas y precisas palabras describía François de LA RochefouCAULd ese sentimiento que embarga a casi todos los mortales. Nuestra época acepta con demasiada facilidad la idea de que la muerte es la aniquilación total y definitiva del hombre y, por consiguiente, prefiere «olvidan» la muerte. Sabemos que tenemos que morir, y vivimos como si estuviéramos seguros de vivir esta vida eternamente. El miedo a la muerte provoca rechazo e incluso menosprecio hacia todas las actividades que rodean el fin de la existencia humana. De ahi la falta de preocupación por estas cuestiones y el abandono en que se ha visto sumido el Derecho mortuorio en nuestro país '. No así en otros, lo cual quizá tenga que ver con esa falta de previsión y ese "vivir al día» que caracteriza al español.

Sin embargo, pocas actividades resultan tan imprescindibles para el hombre como los servicios mortuorios. $\mathrm{Y}$ pocas son tan relevantes y próximas para los ciudadanos como aquellas actividades cuya prestación y establecimiento ha correspondido tradicionalmente a los Entes Locales. Asimismo, en el panorama del Derecho Administrativo, el estudio de estas cuestiones resulta de enorme actualidad, habida cuenta de las profundas transformaciones jurídicas a las que están siendo sometidas. El profesor GARCiA DE COCA no ha desconocido estas circunstancias y se ha enfrentado con valentía a un trabajo de esta naturaleza.

Para los posibles lectores, a pesar de los temores que suscita el desenlace dramático de nuestras vidas, éste es un libro editado con primor que invita a ser abierto. Su autor, como el barquero que conduce el cuerpo de Elaine en la portada del libro - bellísimo cuadro prerrafaelista de John Atkinson Grimshaw (1836-1893) — nos invita a iniciar este viaje para desentrañar con su ayuda los entresijos de las pompas fúnebres.

De elegante presentación, el libro, por su naturaleza, solicita un lector reposado, atento, amante de la palabra, lúcido. Especialmente lúcido, pues si bien en su conjunto la obra es diáfana, algunos párrafos resultan tal vez demasiado densos.

Desde las páginas introductorias el autor hace una declaración de intenciones: desea poner de manifiesto que alguno de los servicios públicos locales ha perdido su razón de ser y que «otras fórmulas juridicas diferentes y más apropiadas pueden ofrecer unos resultados en beneficio del ciudadano superiores a los que hasta ahora ha ofrecido la técnica del servicio público, o, al menos, que otras técnicas colman de igual manera los intereses públicos en juego, con la ventaja de ser más coherentes con la economia de mercado» (pág. 13). Enlaza así con las recomendaciones que en 1994 realizó el Tribunal de Defensa de la Competencia y que se materializaron dos años más tarde en el Real Decreto-Ley 7/1996, de 7 de junio, sobre medidas urgentes de carácter fiscal y de fomento y liberalización de la actividad económica, con el que se despublifican los servicios mortuorios. Y se despublifican, matiza el autor, la totalidad de las actividades comprendidas bajo el término «servicios mortuorios», no exclusivamente los servicios fünebres. Desde el momento en que rea-

\footnotetext{
1 Seria injusto no matizar la apreciación que se hace en el texto, pues aun cuando los estudios sobre el Derecho mortuorio español han sido ciertamente escasos en comparación con los existentes en otros paises de nuestro entomo, desde luego, no han sido nulos. No queremos obviar aqui ni su existencia ni tampoco su calidad. Salvo error u omisión por nuestra parte, la aportación iusadministrativista española ha sido la siguiente: R. Fernandez de Velasco, Naturaleza juridica de cementerios y sepulturas, Revista de Derecho Privado, Madrid, 1935; M. Gonzílez López, «Una municipalización del servicio de Pompas fünebres», REVL, núm. 25, 1946; IBÁNEz Montes, "Uñ aspecto de la policia sanitaria mortuoria: cementerios", El Consultor de los Ayuntamientos, febrero, 1962; M. Segura, Derecho funerario, Libreria Bosch, Barcelona, 1963; F. Lobato BRIme, "Comentario al Reglamento de policia sanitaria mortuoria", Municipalia, núm. 244, septiembre, 1974 y E. ARgullol Murgadas, «La iniciativa de un sector singular en el ordenamiento sanitario", REVL. 1983. No pueden dejar de citarse los estudios del profesor L. Tolivar Alas, Dogma y realidad del Derecho mortuorio español, IEAL, Madrid, 1983; «Los servicios mortuorios locales: Cementerios y servicios funerarios», Tratado de Derecho Municipal, Civitas, Madrid, 1988 y «Expropiación para cementerio: indemnización del perimetro edificable», REDA, núm. 37, 1983. También el profesor GARCin DE ENTERRin se ocupó del transporte fünebre en su articulo "La aplicación de la apariencia de buen derecho como base de las medidas cautelares en el recurso directo contra reglamento", $R A P$, núm. 125, 1991 y, más recientemente, se han ocupado del Derecho funerario Pérez Gálvez y Ochon Monzó.
} 
liza taies afirmaciones logra, comó si de una novela negra se tratara, captar nuestra atención y nos sumergimos de su mano en una vorágine de precisiones sistemático-conceptuales.

No hay duda de que J. A. Garcla de Coca conoce a la perfección el servicio público y sabe dosificar la intriga conceptual, mantener el ritmo y, en resumen, construir argumentos juridicos de verosimilitud insólita. ¿Qué son «servicios mortuorios» y qué «servicios fünebres»? ¿Por qué ciertos servicios públicos locales carecen hoy del sentido que los hizo nacer? ¿Qué técnicas jurídicas resultan más apropiadas que el servicio público?

En contraste con tan misterioso y sugerente comienzo, la preclaridad del índice sistemático de la obra es apabullante. Basta con echarle un vistazo para intuir la racionalidad del discurso del autor. En efecto, el libro consta de cuatro apartados. El primero, introductorio, al que acabamos de hacer referencia, preludia con dosis de suspense el ulterior examen sobre la naturaleza del servicio público y aclara magistralmente la confusión existente entre «servicios mortuorios» y «servicios fúnebres».

El autor aborda en su estudio lo que tradicionalmente se ha entendido por pompas fúnebres 0 actividad fúnebre, es decir, el conjunto de actividades derivadas del fallecimiento de una persona hasta el momento anterior a su inhumación, cremación o inmersión del cadáver en alta mar; excluye, por tanto, la materia necropolitana.

Justificado o precisado el ámbito de su obra y, antes de iniciar el estudio del servicio fúnebre o actividad de pompas fúnebres, el autor nos regala un segundo apartado - sumamente interesantededicado al análisis de aspectos generales, tales como el nacimiento y evolución de los servicios públicos locales en general o las exigencias constitucionales que inciden específicamente sobre este tipo de actividades públicas prestacionales. Las actuaciones prestacionales públicas en el mercado deben someterse a la exigencia constitucional de servir con objetividad a los intereses generales. El autor no niega que los intereses fiscales sean intereses generales, pero afirma con rotundidad que «cuando se pretende la obtención de ingresos por la vía empresarial, aun con la finalidad de servir a un interés público (por ejemplo, reducción de la presión fiscal), se vulnera el principio de proporcionalidad, toda vez que para satisfacer este objetivo existen medios propios, específicos» (pág. 49). En consecuencia, la actuación empresarial pública que sacrifique el interés general al espiritu de lucro propio de la actuación empresarial privada carece de justificación por vulnerar el principio de proporcionalidad y debe considerarse ilegítima.
La tercera y cuarta parte del hibro se dedican al análisis de la zigzagueante historia de la actividad funeraria. La elección de los epigrafes de ambos apartados - De la regulación al monopolio fünebre y Del monopolio fúnebre a la regulación- no puede reflejar mejor el vaivén juridico al que se ha visto sometido esta actividad.

El origen del tradicional servicio público local tiene lugar a finales del siglo XIX y principios del $\mathrm{XX}$. A juicio del autor, la secularización de la muerte provocará la asunción de competencias en esta materia por el orden civil, fundamentadas, en un principio, en el mantenimiento del orden público, en la necesidad de dar solución a problemas de carácter higiénico-sanitario. Progresivamente, y a causa de la deficiente técnica regulatoria de la época, se desemboca en la municipalización con monopolio. Pero junto a las exigencias de orden público aparecen espurios intereses de naturaleza fiscal. El monopolio fúnebre era $-\mathrm{y}$ siguió siendo- una solución recurrente para combatir el endeudamiento que padecían las arcas de las Haciendas Locales.

En el capitulo IV, bajo el título Del monopolio fúnebre a la regulación, se analiza el tránsito de una concepción prestacional reservada de la actividad fúnebre a una función pública, la regulatoria.

Considera el autor que el «derecho exclusivo» (el monopolio, en términos económicos) es una técnica excepcional y amenazada. Y sostiene esta opinión con un arsenal de riquísimos argumentos, plagados de matices. Es una técnica de utilización excepcional por la presencia de un interés general de especial importancia, por los principios de eficacia y proporcionalidad y por sus efectos expropiatorios. Pero, además, el derecho exclusivo es, en nuestros días, una técnica amenazada por las nuevas orientaciones que postulan una limitación de la esfera de actuación del Poder público como forma de ampliar la libertad y responsabilidad de los individuos, por las exigencias del ordenamiento jurídico comunitario $y$, finalmente, por la perfección de la técnica regulatoria como alternativa a las soluciones públicas prestacionales.

La reciente supresión en España del monopolio local sobre la actividad fúnebre, heredera de la operada en el Derecho francés, ha supuesto un renacimiento de la técnica regulatoria. «La despublificación - dice el autor, con una retahíla de acertados neologismos (aunque ya consolidados en nuestra doctrina) - debe provocar la re-regulación o neorregulación de la actividad liberalizada, la despublificación regulada» (pág. 120). La despublificación se justifica por la inexistencia de los intereses generales que en su día significaron la conveniencia de establecer monopolios locales fu- 
nerarios. Con el Real Decreto-Ley 7/1996 se liberalizó la prestación de los servicios funerarios, eliminando el derecho exclusivo que anteriormente existía sobre esta actividad. Pero esta norma no se limita a despublificar, sino que además acompaña la supresión del derecho exclusivo de un sistema autorizativo, en el que el ejercicio de la actividad fúnebre se somete a una eventual autorización reglada municipal. En cuanto a las serias dudas de inconstitucionalidad que, por diversas razones, despierta el instrumento legal utilizado para despublificar la actividad, el autor aboga por la necesidad de elaborar una Ley para despejarlas.

El profesor vallisoletano concluye denunciando con acritud y cierto pesimismo las quiebras que el proceso de liberalización puede experimentar como consecuencia de la «debilidad que en nuestro Estado presenta, en algunos casos, el denominado Estado de Derecho económico» (pág. 142). A su juicio, la lúcida supresión en España del monopolio local fúnebre puede verse ensombrecida por la conversión de los anteriores derechos exclusivos en empresas públicas locales protegidas que compiten con las empresas privadas teóricamente en igualdad. La realidad de las cosas pone de manifiesto que los Municipios no han privatizado las empresas gestoras de los viejos monopolios, sino que las han adaptado al nuevo marco jurídico y las han protegido mediante nuevas Ordenanzas locales reguladoras del ejercicio de la actividad.

Antes de terminar hay dos aspectos de este libro que merecen ser destacados. En primer lugar, las referencias al Derecho comparado, especialmente al francés, el belga y el italiano, no conforman un bloque monolitico y aparte - meramente erudito $y$, como por desgracia ocurre en tantas ocasiones, fácilmente prescindible - sino que se derraman por todos los apartados del libro, alumbrando los argumentos del autor $\mathrm{y}$ ofreciendo interesantes elementos de contraste.

En segundo lugar, es digna de resaltarse también la abrumadora bibliografia que maneja el autor. No sólo por la abundancia de citas o referencias, sino por lo bien seleccionadas que están y por la manera en que el profesor GARCía DE COCA las integra en el texto que, lejos de convertirle en un maestro de la «segunda mano» o del collage, confieren a su verbo un cultismo y refinamiento muy distante de la petulancia o la mera erudición.

A buen seguro, el lector de la obra recensionada comprobará satisfecho que el hecho de que quien emite estas opiniones conozca y aprecie al autor, no desmerece la verdad y justicia de cuanto aquí se ha afirmado. Se trata de un buen libro, escrito con pasión, que transparenta un gran rigor y esfuerzo intelectual, y que ha de tenerse en cuenta en la polémica sobre el «sen» del servicio público y su futuro. El profesor GARCIA DE COCA nos ha iluminado el camino. Merece la pena acompañarle.

Helena Villarejo Galende Departamento de Derecho Administrativo Universidad de Valladolid

González Pérez, Jesús: Manual de Práctica Forense Administrativa, Civitas, Madrid, 5. edición, 1999, 419 páginas.

En esta nueva edición de su obra, Jesús González Pérez profundiza en la tutela de los derechos e intereses legítimos de los ciudadanos frente a la Administración pública y analiza las diferentes vías jurídicas reconocidas para garantizar un adecuado control de la actuación administrativa.

Consciente de la necesidad de sistematización surgida en esta materia a raiz de las recientes modificaciones legislativas, el autor realiza un estudio sistemático y detallado de la Ley 30/1992, de Régimen Jurídico de las Administraciones Públicas y del Procedimiento Administrativo Común, modificada por la Ley $4 / 1999$, y de la nueva Ley 29/1998, de Jurisdicción Contencioso-Administrativa, con las reformas en materia de justicia administrativa introducidas por la Ley 50/1998, de 30 de diciembre.

Fiel a esta vocación de exhaustividad, el trabajo recensionado comienza por dedicar un apartado importante a la aplicación del Derecho y, concretamente, a las tres operaciones en que se descompone: elección, interpretación y actuación de la norma.

A partir de aquí, se reconstruye el sistema previsto por nuestro ordenamiento para la defensa y tutela de los derechos e intereses legitimos. Se exponen de forma clara y rigurosa las reglas generales necesarias para la definición de sujetos, objeto, lugar y tiempo de la actividad, asi como forma de los actos.

Asimismo, se estudian pormenorizadamente los diversos cauces contemplados en nuestra legislación y sus especialidades. Encuentran acogida en esta obra el procedimiento administrativo, el proceso contencioso-administrativo, el proceso constitucional y los procesos ante Tribunales europeos (Tribunal Europeo de Derechos Humanos y Tribunal de Justicia de las Comunidades Europeas).

Se ofrece al operador jurídico un manual encuadrado en una perspectiva eminentemente pragmática. Los privilegios de los que goza la Administración en sus relaciones con los particulares, ha- 
cen dei proceso contencioso-administrativo un control, normalmente, a posteriori de su actuación. Entiende el autor que la tutela efectiva de los derechos e intereses legítimos exige, en muchas ocasiones, ir más allá. Se pretende dar solución a los problemas prácticos nacidos al albur de la nueva normativa, a la vez que llamar la atención sobre las diversas vías abiertas para la impugnación de la actuación administrativa y que permiten huir del reduccionismo al ámbito exclusivamente judicial.

Anabelén Casares Marcos Área de Derecho Administrativo Universidad de León

\section{GONZÁlEZ-VARAS IBÁÑEZ, Santiago: $C o$ - mentarios a la Ley de la Jurisdicción Con- tencioso-Administrativa (Ley 29/1998, de 13 de julio), Tecnos, Madrid, 1999, 641 págs.}

Como es conocido, la aprobación de la nueva Ley reguladora de la Jurisdicción Contencioso-Administrativa ha supuesto la aparición de un considerable número de estudios doctrinales referentes a tal acontecimiento legislativo. La pluma de la doctrina, cargada desde hacia ya tiempo a la espera de esta noticia, se ha revelado, en efecto, especialmente prolifica en un campo que, por otra parte, no puede desconocer su particular atractivo para el estudio, dada su absoluta trascendencia, más aún cuando venía siendo abonado desde hacía años por un incesante y enriquecedor tratamiento doctrinal (por todos, Eduardo GarCiA DE ENTERRIA, Hacia una nueva justicia administrativa, Civitas, Madrid, 1992). En este contexto, justamente, es donde hace su aparición el libro recensionado, en un propósito, como anuncia el mismo autor, de «explicar los distintos temas y artículos de la nueva Ley reguladora de la jurisdicción contencioso-administrativa, siguiendo su propio orden de exposición», prestando, a la vez, «una singular atención a su aplicación práctica o judicial y a los cambios concretos que provoca sobre la jurisprudencia».

Los Comentarios a la Ley de la Jurisdicción Contencioso-Administrativa de GonzÁLEZ-VARAS, aparte de ofrecer al lector un vasto y riguroso estudio de la reciente normativa reguladora del contencioso, en una loable exhibición, además, de los últimos datos legales, doctrinales y jurisprudenciales con incidencia en la materia, proporciona al que se enfrenta con este tema un análisis crítico de las diferentes cuestiones y problemas que se plantean, con una profundidad y dominio sólo alcanzables por quien ha sido, de hecho, uno de los estudiosos de la reforma del contencioso. El profesor
Gonzalez-Varas, en efecto, presenta este estudio general de la Ley 29/1998 como la culminación de una brillante secuencia de trabajos relacionados con la justicia administrativa, gestados en el momento mas crítico de la discusión doctrinal, tales como La Jurisdicción Contencioso-Administrativa en Alemania, Civitas, Madrid, 1993; Problemas procesales actuales de la Jurisdicción Contencioso-Administrativa, Premio «Poder Judicial» 1993, Consejo General del Poder Judicial, Madrid, 1993; o La via de hecho administrativa, Tecnos, Madrid, 1994. No en vano algunos de los aspectos más sobresalientes de la reforma operada por esta Ley 29/1998 venian siendo ya propugnados, junto a otros sectores de la doctrina, por el autor de estas obras. Desde la genérica propuesta de un modelo subjetivo del contencioso, donde primara no tanto el control de la legalidad administrativa como la satisfacción de los derechos de los recurrentes, y su concreción en un sistema procesal administrativo prestacional, hasta el concreto problema de la vía de hecho como incentivo para una mejora y flexibilización de la Jurisdicción contenciosa en detrimento del interdicto civil como solución procesal, han supuesto todos ellos postulados defendidos ardientemente por el autor.

Particular protagonismo, en el entramado del estudio, representa la idea de la concepción subjetiva de la justicia administrativa y el definitivo destronamiento del acto en la nueva Ley de lo contencioso. Lo establecido en su exposición de motivos de que «los escasos preceptos incluidos en los dos primeros capítulos del Título III (referidos, respectivamente, a la actividad administrativa impugnable y a las pretensiones de las partes) contienen algunas de las innovaciones más importantes que la Ley introduce en nuestro sistema de control judicial de la Administración» se compadece perfectamente con el contenido de esta obra, cimentado claramente en tales cuestiones, como asi lo evidencia el propio capítulo introductorio, dedicado precisamente a llamar la atención sobre tal problemática. Pues bien, es justamente esta capital disyuntiva entre el modelo objetivo o proceso al acto $y$ el modelo subjetivo la que permite proponer alguna reflexión.

Como bien es sabido, una de las asignaturas pendientes de nuestro contencioso con anterioridad a la actual regulación era la pervivencia de la concepción revisora en el sentido de sólo admitir la apertura del proceso cuando existía disposición o acto impugnable (un intento de superación de este sistema representó la STC 136/1995, de 25 de septiembre; vid. un comentario a la misma en Tomás QuiNTANA LOPEZ, «¿La inactividad del Jurado Provincial de Expropiación: acto administrativo presunto?», La Ley, n. ${ }^{\circ} 4021$, 23 de abril de 1996). Una limitación de graves consecuencias que finalmente se ha visto superada con la actual Ley 
29/1998 al abrir ésta las puertas del recurso contencioso frente a cualquier comportamiento ilícito de la Administración: no sólo contra disposiciones o actos impugnables, sino también contra la inactividad de la Administración, así como contra sus actuaciones materiales constitutivas de vía de hecho. Corolario de ello ha sido la reforma introducida en el capitulo de las pretensiones, ante la necesidad de ajustar las mismas a las nuevas actividades impugnables. Constatado este dato, cabe entonces plantear el interrogante de si la reforma ha incidido, en puridad, en materia de pretensiones, o si, por el contrario, la gran novedad legislativa ha estribado, en realidad, en el capítulo de la actividad administrativa susceptible de recurso, viniendo a suponer las modificaciones de las pretensiones una mera adecuación a aquella reforma. En este sentido, podria sostenerse la tesis de que, lejos de considerarse todavía no superada esta problemática de las pretensiones en la actual Ley, la misma, incluso, se habría visto solventada en la antigua Ley de 27 de diciembre de 1956, desde el momento en que su art. 1.1 fijaba ya el objeto del recurso, no en los actos o disposiciones administrativas, sino en las pretensiones que se pudieran deducir en relación a los mismos, y, lo que es más importante, desde el momento en que su art. 42, junto a la pretensión anulatoria o impugnatoria del acto o disposición, reconocía la pretensión de plena jurisdicción que hoy sigue consagrando el art. 31.2 de la vigente Ley. A partir de esta conquista de la Ley de 1956, el lastre del proceso revisor habria quedado entonces exclusivamente enquistado en lo que se consideraba materia objetiva susceptible de recurso — siendo ello justamente sobre lo que habría incidido la capital reforma de la Ley de 1998 - teniendo en cuenta que, una vez abierto un proceso, la pretensión de reconocimiento de una situación jurídica individualizada $y$ adopción de las medidas adecuadas para su pleno restablecimiento suponía - y supone - una fórmula lo suficientemente amplia como para asumir cualquier pretensión del recurrente, incluida la de condena, encontrándose en cuanto a este aspecto plenamente garantizada la tutela judicial efectiva. $\mathrm{Y}$ es que, ciertamente, una cosa es lo que la jurisprudencia contencioso-administrativa ha podido o querido deducir de la normativa, y otra muy diferente lo que la Ley de 1956 ya permitia a tenor de su articulado. Como ha ocurrido en otras materias del contencioso - así, por ejemplo, en cuanto a la ejecución de los fallos-, la precedente Ley reguladora de esta jurisdicción encerraba, en realidad, muchas más posibilidades que las que de hecho se supo extraer de ella. Por otra parte, y ya en relación a la vigente Ley $29 / 1998$, puede advertirse que, si bien la misma vuelve a consagrar en su art. 31 las pretensiones anulatoria y de plena jurisdicción, esta última, aparte de no aparecer ya condicionada a una concreta legitimación, no es concebida necesariamente como complemento de la primera, lo que quizá pueda cohonestarse con la actual regulación del silencio negativo, en cuanto que el mismo no da lugar, en realidad, a un verdadero acto presunto, limitándose su virtualidad a «permitir a los interesados la interposición del recurso administrativo o contencioso-administrativo que resulte procedente» (art. 43.3 de la Ley 4/1999, de 13 de enero).

Luis Ángel Ballesteros Moffa Universidad de León. 